\title{
Mergers in South African higher education: theorising change in transitional contexts \\ JONATHAN JANSEN*
}

ABSTRACT Drawing on a study of five merger cases in recent South African higher education, this article examines why in each case, the mergers proceeded despite intense opposition from the entities affected and in a form and manner different from that envisaged by their state designers. It considers too, the inadequacies of existing merger theories to explain these two factors and draws on contingency theory to show how the merger outcomes were the product of a complex interplay between governmental macro-politics and institutional micro- politics in a context of political transition. It also exposes the assumption that policy implementation is a rational process in which institutional practice mirrors the formal intentions of government planners, arguing that the merger process in South Africa has to date been marked behaviour and action that has been both irrational and incoherent as well as not necessarily in the interests of the higher educational process.

This research was motivated by two related puzzles. First, that all the proposed mergers in South African higher education proceeded despite intense political resistance from various constituencies. This requires explanation, for it has not been uncommon in other cases of state-mandated mergers that the designated partners decided not to pursue the merger, and either to continue as separate institutions or to delink after the merger. Second, that the planned mergers unfolded in completely different ways, even though the legal and planning script for these unions were often tightly framed. We have shown elsewhere ${ }^{1}$ that the ways in which mergers unfold is relatively independent of the combination of legal, policy and resource 'instruments' mobilised by government to steer the institutions in a preferred direction, Existing theories of merger were found inadequate to explain such merger trajectories in transitional contexts and a new theoretical platform - contingency theory - is proposed. Contingency theory explains merger outcomes as the product of the complex interplay between 'governmental macro-politics' and 'institutional micro-politics' in transitional contexts.

This article draws on data contained in a large research project involving five case studies of mergers or 'incorporations' in South African higher education (Jansen et al., 2002). The five case studies concern the incorporation of the South African College of Teacher Education (SACTE) into the University of South Africa (UNISA); the Johannesburg College of Education (JCE) into the University of the Witwatersrand (Wits); Giyani College of Education (GCE) into the University of Venda for Science and Technology (UNIVEN); the merger of the ML Sultan (MLS) Technikon and Technikon Natal (TN) to form the Durban Institute of Technology (DIT); and of the Faculties of Veterinary Science (FOVS) of the Medical University of South Africa (MEDUNSA) and the University of Pretoria (UP). 


\section{Theory and the problem of mergers in higher education}

The major monographs on mergers in higher education treat theory in very different ways. Theory, in these writings, receives inadequate treatment for explaining the meaning and trajectories for inter-institutional combinations in transitional contexts.

A first observation concerns the atheoretical posture in these writings. They provide detailed descriptions of specific events and localised incidents which, though often fascinating, hold little generative power for reflection beyond the peculiarities of the case and the context in question. A second observation about studies on mergers is that they tend to rely largely on varied organisational theories to explain the determinants, course and effects of mergers. The most commonly cited of such theories concerns resource-dependency theory. One of the principal knowledge claims associated with resource dependency is that organisations engage in mergers as a result of the threat of diminishing resources. Organisations - like biological organisms - respond to change because of threats in the external environments. In other words, organisations conform to what is required when their survival is under threat because of the fear, real or perceived, that the resources that sustain them might be curtailed. There are several problems with this theoretical orientation. It assumes that organisations are rational, when, in fact, there is enough evidence in our cases that institutions resist even when the benefits for both the institutions and the wider society when resources are shared, expertise consolidated and deficits reduced are clear.

A third observation about the existing studies is that politics and political explanations sit uneasily within the dominant theories for how and why mergers happen. While politics is acknowledged, it is treated either as an organisational sideshow, disconnected from the merger process and its outcomes; or it is listed as a secondary feature of institutional change, dominated by organisational dynamics and networks; or it is identified, then ignored, as if resource dependency obliterates causal explanations based on conflict and contestation; or it is regarded as a purely institutional phenomenon, delinked from the broader politics of state and society.

Donald Zekan is one of the few critics of the detachment between 'institutionoriented' studies of mergers and the macro-political environment in which such actions are embedded - especially in public higher education. His view is that:

the most appropriate focus for public sector mergers is away from institutional organisational characteristics and toward the complex relationships between institutional mission and public policy. In this context, a crucial factor for the success of public sector mergers becomes the interplay of public policy and institutional mission within local and regional political structures. ${ }^{2}$

This thesis about the 'interplay' between institutions and their political environments coincides with our theory of contingency for explaining the course and outcomes of mergers. But our position is not simply one of 'institutional mission' but institutional micro-politics; nor do we simply regard formal 'political 
structures' as the interface with institutions, but state macro-politics expressed through a range of agencies, including the government bureaucracy responsible for education. Contingency theory is not, therefore, about the formal arrangements for politics but the complex of political interactions - conflicts, contestations and compromises - that fuel and frustrate the trajectory of a merger.

\section{Contingency theory: a conceptual platform for a theory of mergers}

In presenting a theory of why, how and with what consequences mergers happen in transitional contexts, our theory of contingency foregrounds political explanations for merger policy and practice. Informed by thick descriptions of the case studies of mergers, contingency theory is derived from a principal proposition that can be summarised (and then unpacked) as follows: the origins, forms and outcomes of mergers are conditioned by, and are contingent on, the specific forms of interaction between institutional micro-politics, on the one hand, and governmental macro-politics, on the other, especially in turbulent or transitional contexts.

Contingency theory, then, gains its theoretical validity from five inter-related core concepts that, read together, provide the scaffolding for understanding the broad theoretical stance being proposed.

\section{The transitional context}

In developing countries, radical changes in education (including higher education) are often invoked by dramatic changes in political regime, such as happened at the end of colonial rule in Africa or following the collapse of authoritarian regimes in Eastern Europe and Latin America in the 1980s. In established democracies, wide-scale reforms in education are often the result of changes in government from one electoral contest to the next; from time to time, such changes in government are fuelled by new ideological positions based on perceived changes in economy, institutions and society. Mergers, as one form of educational change, also typically have their origins in broader social changes. For example, in Australia, the Labour government of the late 1980s pursued 'a set of dramatic reforms ... in higher education [that] was driven mainly by a global reform agenda, bringing into play both the market and the institutions'. One effect was that federal funding became dependent on specified student numbers. In that context, institutional size was understood to be the principal criterion for federal support and the universities scrambled to find merger partners. ${ }^{3}$

In South Africa, the transition from an apartheid state to a post-apartheid society created the conditions for fundamental changes to all levels of education, including higher education. But what were the transitional conditions facing higher education at the end of apartheid era?

First, it was (and remains) a system divided by racial inequalities with white and black institutions bearing the markings (material, cultural and social) of their separate histories. Estimations of 'gross participation rates' (GPR) for the age- 
group 20-24 suggested that for African students five years on from the transition, the GPR stood at 12 per cent compared to 39 per cent for Indians and 47 per cent for white South Africans. Worse still, African students were heavily concentrated in the humanities, arts and education, with only 3 per cent of graduates in engineering, 12 per cent in the natural sciences and 2 per cent in accountancy for the period 1991-98. Similar inequalities held for academic staffing on the eve of the 1994 elections. In 1993, about 87 per cent of academic staff in universities and technikons were white with only 2 per cent and 7 per cent African staff in technikons and universities, respectively. This underrepresentation of especially African students and staff in higher education continued through 2001.

Second, the historically black universities and technikons were - with few exceptions - deeply entangled in ongoing conflict, instability and crisis. Students were in conflict with the institutional leadership over their inability to pay tuition and registration fees; staff were in conflict with vice-chancellors; senates confronted councils; councils were deeply divided among themselves, especially on the issue of management. Sometimes staff and students created a common bloc acting against allegedly corrupt senior managers who were constantly replaced by 'acting' leaders. But the changing nature of alliances among campus stakeholders ensured that the period after apartheid was highly volatile and unstable in black technikons and universities. Fuelling much of this instability was the high levels of student debt and the steadily declining fall in institutional revenues, leading many to depend on bank overdrafts to keep their institutions afloat. Much government money was spent in this period (1994-2000) on commissions of inquiry as violent confrontations continued long after the first democratic elections.

Third, South African institutions witnessed a dramatic and unexpected decline in student enrolments, a trend that had particularly devastating consequences for the struggling black universities. In 1999, for example, total headcount enrolments (universities and technikons) dropped by 41,000 students (or 7 per cent) from the previous year - starting a downward spiral in especially university enrolments over the next three years. Worse, in 1998 only 69,000 students gained matriculation exemption (enabling direct entry into university) - a far cry from the 130,000 predicted by the National Commission on Higher Education (NCHE). What this meant was that there were fewer students, and fewer good students, to occupy the first-year spaces at universities. More devastatingly, the few good students, black and white, now both enjoyed access to the urban, better-resourced and former white universities. The consequences for black universities was immediate, direct and devastating: fewer students were admitted, and those who were drawn to the historically black universities (HBUs) were more uniformly poor, under-prepared and desperate for higher education but without the ability to pay. It was this dramatic shift in enrolments (both quantitatively and qualitatively) that played a significant role in the collapse of HBUs in the mid- to late 1990s.

Fourth, South Africa inherited a plethora of post-school institutions that included 21 universities, 15 technikons, 120 colleges of education and 150 technical colleges - quite apart from a growing private higher education system and a 
large, unspecified (at the time) independent and voluntary further education sector. All the public sector institutions were created on the basis of race, language and ethnicity under the apartheid system. There were six white Afrikaans-medium universities and four white English-medium universities; four centrally controlled universities for 'Africans'; one each for 'Indians' and so-called 'Coloureds' and four universities located in the former 'independent homelands' for African students. There were seven historically white technikons (also divided by language) and seven historically black ones. In addition, there was one distance education technikon and a large distance education university. In short, the new government inherited an institutional landscape which was 'shaped, enlarged and fragmented with a view to serving the goals and strategies of successive apartheid governments'.

The black institutions were mainly located in under-developed, impoverished rural areas with little economic infrastructure for supporting local development and university expansion. In short, South Africa inherited a wide range of institutions spread thinly and unevenly over urban and rural areas with considerable variation in their capacities for teaching, research and development. For example, despite the explosion of institutions, two of the nine provinces have no universities and technikons (that is, the Northern Cape and Mpumalanga). Given the racial origins of these institutions, the distribution of higher education was highly inefficient and even illogical, with similar institutions sharing fences (as in the KwaZulu Natal technikons) or expensive institutions located in close proximity to each other (like the Faculties of Veterinary Sciences).

It would be difficult to understand the restructuring of higher education without grasping the nature of this transitional context from apartheid rule. However, the specific policy and planning instruments selected for reshaping higher education can only be understood by examining the macro-political environment of the late 1990s.

\section{The macro-political environment}

In South Africa, the radical change of government that accompanied the shift from the apartheid to a democratic state triggered widespread changes in higher education, particularly with the appointment of the second postapartheid Education Minister, Professor Kader Asmal. He brought to his task a strongly interventionist policy seeking the mergers of post-secondary institutions across the board - universities, technikons, colleges of education and technical colleges. He motivated the call for mergers through reference to the apartheid system whose higher education institutions reflected 'the geopolitical imagination of apartheid planners' and argued that there was a past to be resolved through the creation of a single, coordinated system of higher education without racialised inequalities. There was also another motivation, though less pronounced in public-policy discourse, and that was the need to incorporate the South African higher education system within fast-changing, technology- driven and information-based economies described under the rubric of globalisation. 
It is in these twin logics of the transition that the proposal for mergers must be understood - the logic of resolving the apartheid legacy in higher education, and the logic of incorporating the higher education system within the context of a competitive, globalised economy.

The first logic seeks to deal with the race issue, i.e. how to reduce the inequalities of resources between black and white institutions, as well as creating greater equity with respect to staffing and students within the former white institutions - what I have called elsewhere 'restructuring'. The second logic deals with the rationalisation issue. i.e. how to create a streamlined, efficient and effective higher education system that is competitive within the global economic system - again labelled elsewhere the rational imperative in higher education restructuring'. Without an understanding of these political imperatives of transition, it is difficult to comprehend the nature and intensity of the contestation that has accompanied the merger process and outcomes in South Africa. How were these macro-political considerations expressed through the merger cases described in this volume?

Both university and college reorganisation have their roots in the transition to a new government. The first post-apartheid Minister of Education, Professor Sibusiso Bengu, commissioned the National Commission on Higher Education, drafted a succession of Green and White Papers on higher education and set the platform for the possibility of restructuring the postsecondary system as a whole. But little was in fact, done under him. By the time Asmal took office in 1999, a more stringent macro-economic programme heralded efficiency, reduction in government expenditure, and a general climate of austerity. By this time too, universities and technikons - especially historically black institutions - had become both a political embarrassment to government (because of a series of very public upheavals, including violence and killings on campuses) as well as a financial challenge - because of highly publicised deficits running into tens of millions of rand in several institutions. The euphoria of development was replaced with the realities of austerity.

All five mergers studied here, and indeed all the mergers underway at the time of writing, were strongly directed by government through a mix of politics, legislation and persuasion. Even in the case of the technikon case study, ostensibly a voluntary merger, it was government that both lubricated the merger in the early days through a R3 million facilitation grant, and that insisted on the merger being concluded in the latter stages, when the process threatened to come apart. It is this macro-political context that is crucial to understanding the merger imperative, despite intense political resistance at the institutional level.

The political role of government was also demonstrated in powerful ways in the case of the college mergers. The most striking incident involved the Johannesburg College of Education (JCE) which, in a demonstration of its own authority in the mergers, announced that it was contemplating a merger with Technikon Witwatersrand - a nearby higher education institution. What followed was a gentle reprimand to the Rector of the College by the Minister of Education, and a less than subtle redirection into incorporation with the 
University of the Witwatersrand, Government used its authority to steer an autonomous higher education institution into its (government's) preferred partner rather than JCE's chosen partner. Similarly, when Giyani College decided to pursue its own merger partner it was instructed to merge with another institution despite arguments about greater distance and the lack of a tradition of partnership with the latter institution.

But the role of government was not always one of positive assertion; it was, at other times, one of benign neglect. This is most clearly demonstrated in the case of the SACTE-UNISA merger. In this case, UNISA (the major partner) broke every rule in the merger boot: it ignored the Public Bargaining Sector Agreement on the recruitment and hiring of college staff; it absorbed all the SACTE students without taking any of their staff onto the university establishment; it reluctantly incorporated the SACTE curriculum but with only a temporary reprieve for college staff, to design and complete the curriculum development process and, then, leave. Not a single SACTE staff member was placed on the establishment of UNISA. What did government do? It stood back, conceding the possibility in the interviews for this study of a moral lapse but not conceding any ethical or political lapse. In this regard, both the national and the provincial government (the latter being the employer of college staff) refused to respond to what, on the surface, appeared to be an illegal incorporation or, more accurately, no incorporation at all.

It is this combination of political assertion and political neglect that begins to fill out the macro-political picture with respect to the role of government. The political nurturing of these mergers by government explains why they all happened (as a legal reality), beyond what was required by legislation and policy. What macropolitics does not explain, however, is why the mergers happened in such different and unplanned ways, or not at all (as an educational reality).

\section{The micro-political arena}

None of our case-study mergers were uniformly and consistently welcomed and pursued by the institutions concerned. Indeed, the government's announcement of the intended merger created deep concern among all levels of staff, from academics to administrators to technicians to clerks to maintenance workers. Before, during and after the mergers, there remained widespread concern about job losses, uncertainty about personal careers, anxiety about institutional futures, myths about who would (or would not) be retained, fears about the loss of autonomy on the part of the weaker partner, perceptions about white staff being advantaged over black staff, or black staff being 'affirmed' over white staff, and a general loss of morale on the part of all.

What the case studies further revealed was the considerable variation in reaction of the staff to these mergers. In some cases, there was outright contestation by the unions directed at government (the technikons); in other cases, there was intense contestation about the terms of engagement directed at the stronger partner (Giyani-Venda); and in yet a third case, the 
institution itself was divided among its leadership (SACTB-UNISA) about the merger proposal and its processes. In general, however, there was no widespread challenge by staffing unions or their membership against the mergers even though deep resentment and rivalry characterised the institutional micro-politics.

Where the real politics played itself out was in the leadership of the weaker institutions. The SACTE case is instructive. The Rector was clearly against the merger, and his position was consistently held throughout the merger process. Quite simply, he rejected the merger out of hand. The counterbalance to his leadership came, however, not from government, but from the rest of the SACTE leadership, which gradually assumed control of the merger process. The Rector resigned, and an interim leader from the partner institution (UNISA) replaced him. SACTE went into this merger without strong leadership and, eventually, without any leadership. The shape of this merger was directly affected by the poor leadership of the weaker partner. Rather than establish a strong bargaining role with UNISA that would protect its staff, invoke labour relations agreements, and require government intervention and support, the SACTE staff was left exposed, vulnerable and without any status in this merger. To put it bluntly, there was no merger; instead, SACTE was incorporated as a sub-division of the University of South Africa. None of its staff was absorbed, student numbers were recorded on the UNISA balance sheet in the form of much-needed subsidy income for the Faculty of Education, substantial reserved from SACTE were transferred to the university, and a form of curriculum was taken overdeveloped by the nonestablished SACTE staff.

The way in which this merger unfolded is a direct result of the institutional micro-politics at SACTE, but in this process, the micro-politics of UNISA was not irrelevant. For UNISA, the SACTE incorporation was completely unattractive: they would not gain the SACTE physical plant, since the provincial government would retain it or, as later appeared, negotiate its future with other institutions. In addition, UNISA's Faculty of Education (the entity that would actually incorporate the college) had experienced dramatic declines in student numbers (with a direct implication for the subsidy of UNISA) and had already signaled the possibility of staff rationaiisation. The SACTE incorporation therefore represented a threat; the timing was simply wrong. So, a confluence of circumstances generated a lukewarm posture towards the SACTE incorporation, the material benefits notwithstanding. In short, the lack of determined leadership on the part of SACTE, and the reluctance of UNISA to engage in the merger in the first place, made this, as the case author once suggested, 'a case of immaculate conception'.

The institutional micro-politics in the JCE-Wits case also had a strong determining effect on the form that the merger eventually assumed. If SACTE had no leadership, JCE enjoyed exceptionally strong leadership that directed, from beginning to end, favourable terms for the incorporation into the large and influential Wits University. The college could ensure that it remained physically intact as a unit, to this day calling itself 'The College of Education at Wits' - not simply as an understanding among the partners, but as a public 
marker of the college's status. The college circumscribed the use of its reserves for purposes of teacher education. The college negotiated professorships for its senior staff, even though this defied the established rules for academic promotions (such as research and publication), generating not a little consternation among junior academic staff in the university's Department of Education. The college leadership reported to the Dean of Humanities, not to the Head of the School of Education, thereby elevating the Head of the College to the same status as the Head of the School in terms of the university hierarchy: no other college-into- university incorporation achieved such a feat. The college leadership rallied the college staff on the basis of its (self-described) strong professional identity, to establish a sense of common purpose, a unity of position that carried through to the negotiations with the university. While the college might not have had free choice of partners, because of decisive ministerial intervention, it had everything else: strong position and status within the university, operating as a quasiindependent facility for the pre-service training of teachers.

\section{Merger formations}

In all the mergers concerned, the specific interaction of governmental macropolitics and institutional micro-politics shaped the form an8 content of the merger, leading either to institutional obliteration (as in the case of Giyani and SACTE), or protected enclosure (as in the case of JCE) or subsumed integration (as in the case of the Veterinary Faculties) or equal partnership (as is likely to be the case with the two technikon mergers).

By institutional obliteration we mean the disappearance of the college entity in its entirety, even though residual components of the original partner might reside in the curriculum or faceless students might be entered onto the books of the powerful staying partner. In the case of Giyani, the physical plant was simply taken over (at least that is the plan) for the establishment of the Agricultural School of the university. There were very few students to take over; in fact, it appears as if the ongoing decline in student intake, made worse by the failure to develop an institutional strategy for recruitment and registration in 2002, might in fact mean that no new students will transfer from the college to the university. The college curriculum, richly endowed with professional knowledge and widely regarded as a centre for innovation in teacher training, was simply ignored by the university. The lack of interest on the part of the provincial government, and the lack of attention on the part of the university, simply led to the disappearance of the college as an entity; in policy terms, there was no 'sub-division' to be created within the university.

By protected enclosure we mean the continued separate existence of the merged entity (the JCE College case) within the new institution. This does not mean that the JCE does not work within broad institutional obligations, like any other academic unit or facility at the University of the Witwatersrand. It simply means that it was able to secure a separate dispensation of finances (the reserves), appointments, promotions, reporting lines, curriculum autonomy and campus status than was allowed in the normal body of institutional regulations governing departments, schools and faculties. Now it 
could be claimed that this is a temporary feature of the incorporation agreement, and that these protected arrangements might well be dissolved after the agreed five-year period; this might be the case. But it is equally possible that initial arrangements could be maintained as the institutions settle into the routines of management and administration under the status quo. By subsumed integration we mean the 'take-over' of a smaller, vulnerable institution into a larger, established institution. In the case of the Faculties of Veterinary Science, the staff was absorbed; the students were taken over; the curriculum of the smaller institution was largely ignored; and the physical facilities were in fact not needed. The culture of the white, dominant, Afrikaans institution, the University of Pretoria, completely subsumed the Faculty of Veterinary Science at the historically black university, MEDUNSA. This does not mean that the black Veterinary Faculty disappeared; in fact, the staff and students remain very much part of the new, combined Faculty. But it remains marginal and vulnerable in terms of physical numbers (staff and students), language practice (Afrikaans rather than English), political space (demands for resources and recognition) and self-determination (future prospects). This is the classical 'take-over' scenario described in merger texts.

By equal partnership we mean the combination of two institutions, both established and with significant physical assets, student numbers and academic staff. This form of merger is unlikely to lead to the dissolution of one of the partners or to any visible downgrading of the status of either partner. It is, in many ways, the ideal-type of merger in which the combined resources of the two institutions lead to a stronger and expanded single institution. In this study, the two technikons represent an equal partnership merger of institutions with similar academic profiles or what the literature calls, a horizontal merger. ${ }^{4}$ It is important to recognise, of course, that the financial status of the two partners remains a matter of contestation in the case of the technikons. The historically white institution clearly has substantial deficits (about R30 million) coming into the merger, but also under-capitalised actuarial deficits on the medical aid (as well as pension) fund needs of the institution. It may be that as the merged entity unfolds in the next few years, that the ML Sultan Technikon might assert itself more strongly in the new institution as a result of its better financial standing, and the fact that the new leader of the Durban Institute of Technology is, in fact, the vice-chancellor of MLS. It certainly appears to be the case that in the first year of the merger (2002) MLS is the much stronger partner in leadership as well as financial terms. But it is difficult to predict what form the merged entity will take in the future; our judgement is that the size of the multi-campus facility, the cancellation of deficits, the strong Technikon Natal contribution in terms of facilities and students, and the pro-vice chancellor status of the former TN vice-chancellor might still make this form of merger an partnership of equals. Staff would be treated equally from both sides; students would enjoy full incorporation from both technikons; the curriculum contributions would take both institutional profiles seriously: and the physical facilities would be shared without loss to either partner. The post-merger process will have to be followed carefully in the next three to five years in order to test these provisional standpoints. 
The theorisation provided up to this point makes the assumption that the precise form that a merger assumes cannot be determined on an a priori basis. Classification schemes based on external features (such as the size of the partner institutions or the disciplinary identities of the partners) do not shed light on the actual form of incorporation. What this study shows is that the ways in which incorporation happens is relatively independent of the physical characteristics of the merger partners or the political, legal and policy claims of what the merger actually is, or will achieve. Rather, the form of merger is determined at the interface of state macro-politics and institutional micro- politics, and understanding how each plays itself out within particular contexts is key to understanding both the form and the future of the merger under focus.

\section{Merger outcomes}

The outcomes of a merger are contingent on the political forces initiating, shaping and sustaining the mergers. Those forces operate at the levels of government bureaucracies (what we call macro-politics) as well as at the levels of institutions (what we call micro-politics). But how exactly is this reflected in the outcomes of mergers? This research used five focal questions for judging and explaining merger outcomes: equity effects, efficiency effects, curriculum effects, organisational effects, student effects, staffing effects and physical effects.

\section{The equity effects}

None of the mergers underway suggest that greater equity has been achieved in terms of either students or staffing. That is, none of the mergers either intended, or achieved, greater representation of black and women students in the new institution. Where this did happen, it was simply a combination of what each institution brought to the merger anyway that is, i.e. a simple addition of staff and students from both entities. The belief among merger advocates, including government, that mergers create stronger equity effects, needs to be debunked. There is no empirical grounding for such an expectation. How is this explained within political contingency as guiding theory?

First, the motivation of government for pushing mergers in the first place had very little to do with equity, notwithstanding official policy claims and expectations. It had everything to do with costs and, more directly, the reduction of costs. The merger of the very expensive Faculties of Veterinary Science was motivated solely by the need to cut expenditure. The incorporation of colleges was driven largely by the need to create a more efficient and streamlined system of higher education, under control of the national government. The co-existence of two expensive technikons, one white and one black, sharing a common roadway in Durban and offering similar engineering and technology programmes, could not be justified in terms of costs. Government intervention was not driven by equity and diversity in any of these cases, but by efficiency and control. And it is for this reason that much of the ongoing contestation between institutions and the 
state centres as much on funding as on fairness, on resources as on redistribution.

From the data generated and analysed in the five case studies, there is actually evidence of a reversal in the overall equity profile of the combined institutions. That is, even when a simple additive model accounts for the staff and student equity profiles of the combined institution, such profiles might in fact weaken under the merger. In the case of the veterinary schools, the only change that resulted in staffing terms was a shift of the largely white MEDUNSA staff, themselves trainees of the University of Pretoria, back to their alma mater as veterinary academics. In practice this meant an even greater number of white and male faculty at UP compared to the situation before the merger with a faculty from a historically black institution. Where there was a marginal increase in the number of black staff, it was at the lower levels of administrative and technical staff. In the case of the student equity profile, the Giyani-Venda merger also indicates fewer students (all black) participating in the combined institution, a function no doubt of the steadily declining numbers of students in teacher education in both institutions, and the lack of recruitment of new teacher education students at the former college campus. It is too early to tell whether the Durban Institute of Technology will experience changes in its staff and student equity profile after the merger. What evidence there is, however, suggests that equity is not an inevitable product of merger, even in cross-racial mergers; that the state does not place a high premium on equity within the modalities of the various mergers (even though high-level policy documents articulate such a goal); and that institutions themselves are not driving equity as a specific issue in the merger process.

\section{The efficiency effects}

In any merger, the first victim is data. It is the very heavily contested nature of the data, both in micro- and macro-political contexts, that made it so difficult in this study to estimate efficiency effects. The most public of these contestations about data was the case of the technikons, threatening to derail voluntary merger near the end of multi-year merger deliberations between the two partners. The staff union at MLST claimed that new information suggested excessive debt and liabilities on the part of NT in excess of R740 million. ${ }^{5}$ The Department of Education sent a small task team to evaluate the validity of these claims, and the status of the finances of the two institutions. The departmental task team delivered a short report, based on a oneafternoon visit in 2002, to the effect that the data presented did not suggest extraordinary liabilities on the part of NT, even though one of the specialists complained that the latter institution could not even present 2001 audited statements. At the same time, the report was clear that 'ML Sultan is in a sound financial position whereas Technikon Natal is currently undercapitalised [and that] good management will be required in the new institution to prevent deficit budgeting and to ensure financial viability'. ${ }^{6}$ The staff unions persisted that there appeared to be irregularities in the financial statements of NT, and threatened withdrawal from the merger; these claims were led, notably, by the chairperson of the joint task team that was supposed 
to manage the financial aspects of the merger. The Minister himself visited the institution and promised, in writing, to write off the confirmed debt (about R30 million) in addition to financing, by about the same amount, the further costs of merging the two institutions, e.g. the costs of a new technological infrastructure for the DIT. In the end, this contestation of financial aspects of the merger might have gained MLS and the DIT a large "chunk of government financing to secure the merger. But it did not end internal speculation about efficiency gains, in part because of the slowness of response on the part of NT in delivering audited financial statements. More strikingly, even after the merger became a legal reality, there was still no due diligence' study on the table, with each technikon employing its own auditors for this purpose, to deliver a scheduled report, six months after the merger was declared!

In efficiency terms, the following conclusions can be drawn form our case studies. First, that efficiency gains were not clearly evident in any of the mergers under investigation. There is no evidence that money was saved as a result of the merger process. Now this could be explained by the fact that the case studies captured mergers in various stages of their evolution; even so, no evidence, even in the positive forecasts, predicts marginal, let alone significant, savings.

Second, that efficiency gains were clearly not realisable in the initial stages of any merger, given the upfront costs of consolidating debts and liabilities, the costs of new infrastructure to accommodate combined staffing and students on single sites, the costs of curriculum development and integration, the costs of building technological alignment and capacity within the new institution, the costs of retrenchment with the inevitable layoffs of various levels of staff, and resolving the differences in salaries between merging institutions. A critical issue in this regard is what a South Africa Universities Vice-Chancellor's Association (SAUVCA) Task Team that sought to determine the one-off costs of a merger called 'the surplus of liabilities over unencumbered assets'. This group rightly observed that 'If liabilities exceed unencumbered assets, a solvency problem is indicated' but then argue that 'it may prove necessary to rectify such cases before mergers can take place'. Only two institutions in South Africa reported surpluses of liabilities over unencumbered assets - the ML Sultan Technikon and the University of Pretoria.

Third, that efficiency gains were almost impossible to determine in terms of proclaimed downstream savings in part because the expectation of savings is strongly contingent on what the institution actually does as it moves along the post-merger pathway. The retention of large numbers of staff (as in JCE) make downstream savings unlikely except if retrenchment is eventually forced on the new institution; and the capacity to generate downstream savings depends crucially on the extent of infrastructure expansion (as proposed by MLS). The exaggerated estimations of costs is what William Massy ${ }^{7}$ calls the administrative lattice: the tendency for administrative and support structures to replicate themselves because of their own internal dynamics. This lattice replicates because needs are perceived as unbounded and because of the tendency towards risk aversion. And the extent of savings depends also on the capacity of merged institutions to at least retain historical levels of student 
enrolments (as in the case of Giyani-Venda), short of which there will actually be losses in the merged entities given that subsidies are determined at least in part on the basis of enrolments.

Fourth, that net efficiency gains are strongly dependent on the nature of the discipline (as in the case of the veterinary sciences) and what the state eventually decides to do about this. Veterinary sciences is by definition a costly discipline that is unlikely to fund itself, i.e. it requires cross-subsidisation from the broader institution as well as from the state. The question is what level of cross-subsidisation is acceptable? For purposes of the argument in this section, efficiency estimations could be high and unsustainable or high but manageable depending on the extent to which the state provides a special dispensation for the discipline. In terms of the theoretical orientation in the study, efficiency is contingent on state action and therefore lies in the realm of macro-political decision-making. But it is also dependent on institutional micro-politics, Le. the extent to which academic faculties are prepared, through the Senate, to live with high levels of cross-subsidisation in environments that have become increasingly conscious of reductions in unit expenditure. Indeed, the financing of veterinary science is one of ongoing dispute and contestation within the University of Pretoria.

Fifth, efficiency gains are difficult to estimate because of the poor state of management information systems in transitional institutions. Data is not systematically collected, managed and utilised. Data (like finance data) is seldom delivered in time to be useful. Data management systems frequently breakdown, like the collapse of the UNIX system at SACTE/UNISA, which immediately obliterated vital data for monitoring and planning purposes. Data systems of one institution are managed through different technologies and administrative systems from the partner institution, creating instant conflict. Data collection is dispersed, so that in the colleges, institutional data (like student enrolments) is kept separately from provincial government data (like salary information) which is disconnected from national government data (like subsidy calculations). What this uneven quality of data and data management allows, therefore, is intense contestation about the meaning of the data, rendering such information subject to manipulation during merger negotiations. The manipulation of student data at SACTE and of financial data at Natal Technikon, are two prominent examples of how efficiency itself becomes part of the contestation around mergers and their consequences.

\section{The curriculum effects}

Does the bringing together of two institutions mean a rationalisation of the curriculum or, at the very least, a use of the combined expertise and materials of the two entities to create a single curriculum? In some cases, the answer is simple: 'No.' In the case of the colleges, SACTE being the most obvious, the college curriculum simply dissipated under the politics of neglect and indifference on the part of UNISA. The same result came about in the case of Giyani College. On the other hand, in the case of JCE, the pre-service curriculum was buttressed in a strong college-school structure and culture that simply continued the status quo, with historical contributions from university 
academics still received as inputs into the college-driven curriculum. In this case, the joint teaching on the Bachelor of Primary Education (the BPrimEd) started with a division of labour in which Wits University staff taught the education theory components and JCE staff the subject methodology components. Despite efforts 'to allow theory to be informed by practice and practice by theory', ${ }^{8}$ the Wits-JCE teams found curriculum integration to be very difficult with Wits tendering to maintain control of the conceptual and theoretical directions of education theory taught.

One of the factors frustrating such curriculum integration has been the familiar argument about teaching being a practical, professional activity as opposed to a theoretical and academic qualification. ${ }^{9}$

In the case of the veterinary faculties, the large institution's curriculum dominated completely, with only marginal accommodation of the smaller faculty's curriculum. There are other models, though not studied in this case collection. At the University of Pretoria, which incorporated the Pretoria Teachers College (OKP), a strong model of integration of the college curriculum into a university curriculum was secured through intense curriculum workshops, the hiring of a new layer of 'outside' academic staff, and cross-school faculty deployment to ensure optimal integration. In other words, the degree of curriculum integration is contingent on the role of leadership. The new leadership of the combined institution could either require and insist on strong integration or allow the new structures (schools within a faculty) to manage their own curriculum or simply ignore the small institutions curriculum or accommodate it marginally.

What was crucial in the contestations over curriculum, and therefore the degree of curriculum integration, was micro-political struggles over whose content matters. In the case of the veterinary faculties, the issue of elite science (parakeets) versus subsistence science (pigs) constituted a major fault line in the debates over curriculum. In a public outburst by a senior MEDUNSA academic on this point, he remonstrated that 'they [Pretoria] provide for parakeets, we provide for pigs'. In the detailed case narrative on the colleges, a persistent theme in the struggles over curriculum authority was the claim by college lecturers that they had better expertise and experience for the training of teachers as professionals. Universities were too academic and theoretical; they had little knowledge of the world of professional practice. In some cases, this argument 'won' (as in the case of JCE); in others, the college was simply ignored as an organisation, including its curriculum (as in Giyani and Venda). It remains to be seen whether and how the technikons resolve the curriculum effects especially since this combination represents a horizontal merger of similar fields.

\section{The organisational effects}

The case studies demonstrate that the degree of organisational integration was a function of conscious political decisions about the accommodation (or non-accommodation) of one of the merger partners. In the case of Giyani and SACTE Colleges, as was demonstrated earlier, the stronger institution made 
the decision to ignore the respective college structure or organisation, and to simply absorb student numbers (and therefore added subsidy) while maintaining the university's faculty organisation without alteration. In the case of JCE, the college remained in name and organisation with minimal adjustments under the university. This position was attained because of the strong and assertive leadership of the previous JCE administration, with the result that there was very little organisational integration between the university department and the JCE organization.

In the case of the veterinary faculties, the MEDUNSA staff, students and curriculum were simply absorbed into the existing departmental and administrative organisation of the large Faculty of Veterinary Science at the University of Pretoria. Despite concerns and contestations of both staff and students at MEDUNSA, the larger organisation simply incorporated the smaller one. In the case of other college-into-university incorporations, two schools were established - one to accommodate the university faculty or department of education, the other to accommodate the incorporated college. These organisational arrangements were in fact, political accommodations, granting the college a degree of insulation and autonomy from being 'swallowed up' by the larger university organisation; this was clearly the case in the University of Pretoria's incorporation of Pretoria Teachers College.

The case of the technikons is likely to be as strongly contested, since the coexistence of similar departments and programmes (as in engineering, for example) means that once the actual merger integration deliberations happen, them is likely to be strong contestation about the terms of organisational restructuring. In the meantime, under strong political pressure to meet the merger deadlines the two Durban technikons combined to form the new Durban Institute of Technology. From a legal perspective, the merger has happened; from an organizational-integration perspective, the actual merger has yet to take place. If the legal establishment of a single institution was so strongly contested, it is likely that the organisational establishment of the new institution is also going to be the subject of fierce battles among the departments of the former technikons. In this case, the organisational effects of the merger remain an open question and are likely to be resolved in the heat of inter-departmental battles.

What is clear, though, is that the organisational arrangements are contingent on macro-political decisions - as in the case of the technikons, who merged under government pressure to meet specified deadlines even though no reorganisation had happened as yet; but organisational structures are also a function of micro-political decisions as to how, even whether, the partner institution would in fact be accommodated in the larger institution.

\section{The student effects}

In each and every merger in these case studies, students in both institutions were concerned and, on occasion, even contested the proposed combinations. In several cases, the students complained about the lack of consultation, the problem of being absorbed into a new institutional culture, 
the loss of identity and 'specialness' of the original institution, and the lack of clarity about their futures. In the case of the technikons, the students waged active campaigns against the merger, working alongside the staff unions in casting doubts on the viability of the two institutions coming together. Despite the strong feelings of discontent, even resentment among students, it is surprising that no studies of mergers really document the concerns of students. In all cases, however, student politics was not a determinant force in the origins, forms or outcomes of the mergers. In fact, student politics was largely ignored under the deliberations on the content and process of each merger. There are several likely reasons for the lack of influence of student politics in the mergers. First, there is the lack of student organisation to contest the mergers. Second, the students most severely affected were at a physical distance from the immediate merger politics (as in the case of SACTE's distance education students). Third, the students affected were a small minority within the large student body and overpowering institutional culture, as in the case of the veterinary faculties. Fourth the students enjoyed protection in the insulated organisational arrangements provided, as in the JCE case, and therefore had little to be concerned about. Fifth, the lack of a strong tradition of student politics in the college sector, contrasted with the universities and the technikons. And sixth, the students from colleges might in fact, have anticipated benefits from the upgrading of their status from lesser institutions to more established institutions, e.g. college diplomas become degrees over time, and a UP degree might carry more weight in the market that a MEDUNSA degree in the veterinary sciences.

The student effects of mergers were therefore, contingent on the status and organisation of student politics, the power, status and influence of the receiving institutions, and the broader imperatives of merger driven at senior institutional leadership levels interfacing with senior political leadership in government.

\section{The staffing effects}

The impact of mergers on staff, in all cases, has been devastating for the emotional and professional lives of all staff, at all levels. ${ }^{10}$ Careers ended abruptly, or were suddenly redirected in ways that were traumatic for the affected staff. In most of the merger cases, staff politics was inconsequential in determining the forms and outcomes of the merger. The SACTE and Giyani College staff, under non-directive leadership, simply had no voice in either their unions or the provincial government or other form to express, direct and represent their grievances and concerns. In fact, the lack of outright aggression and politics were striking features in these mergers, given the recent history of organisational politics in South Africa. But this was not the case with the technikons, where MLS staff unions waged relentless campaigns in the closing months of the merger to stall, even withdraw from, the pending merger with Natal Technikon. In the case of JCE, staff politics was represented in, and supported, their leadership in what it refers to as a 'united culture' that secured important gains - physically, financially, and academically - for the college staff. In short, there were three kinds of staff politics that emerged from the mergers under study: 
(1) Corridor politics: this refers to strong feelings of betrayal and abuse, but not expressed in staff organisation and not supported by government as employee, in the case of two of the college-intouniversity mergers. Anger and resentment was not translated into organised politics against the mergers. In this case, open staff politics was largely irrelevant in determining the form and process that the merger assumed in the identified cases. The use of rumour and mythmaking clearly contributed to the merger climate within the institution, and to a very active micro-politics among staff and management; but it did not alter the speed or outcome of the merger process.

(2) Street politics: this refers to the active representation of staff politics within public spheres, including the media, campus organisation, and through representations directly to government. With the technikons, organised staff unions captured and presented staffing concerns, especially on medical and pension implications, as well as retrenchment costs of the merger. In this case, staff politics was subsumed under and overridden by the negotiations and compromises reached between the upper tier of institutional leadership and governmental leadership. The power of the very demonstrative public protests yielded in the face of state politics and its direction of institutional leadership through the final phases of the merger process.

(3) Boardroom politics: this refers to the active negotiation and securing of position of one merger partner ahead of, during, and after the merger process as a result of deliberate action by managers and leaders. This manoeuving is not public, but private; it happens in boardrooms, not on campus platforms; it happens in small groups, not in mass protests. And the clear case here is JCE, where staffing interests were buttressed against large university politics through astute leadership.

The most effective of the three forms of politics was clearly that of where, having accepted the merger as inevitable, the leadership of the institutions then positioned their individual entity for optimal gains within the merger plan. Corridor politics simply generated frustration in the institutional offices and cafeteria; rumour exacerbated anxiety and uncertainty and, as the SACTEUNISA case demonstrated, was not inconsequential in shaping the experience, if not the outcome, of the merger. Street-level or public politics displayed aggression and threatened withdrawal but did not influence the final outcome of the merger, as the MLST case demonstrated, One of the reasons was the strength of political pressure form central government aid the commitment of the management of the two technikons to simply proceed under governmental direction with the long-awaited, voluntary merger.

\section{The physical integration effects}

The principal finding of our research team is that physical integration is the most complex, messy and drawn-out component of mergers in transitional 
contexts. Furthermore, we found that the range of factors that determine the degree of 'physical integration' is so broad and contentious that no simple or straightforward finding can be made given both legal and political uncertainties about physical site ownership.

Nevertheless, in all cases, the merger promised additional physical facilities and infrastructure to the dominant partner. The promise of expanded infrastructure was not inconsequential in the merger drive, but threw up several ambiguities across the higher education system. In the case of the Giyani-Venda merger, the prime real estate and attractive infrastructure of the college represented opportunities for expansion of the university and the establishment of its School of Agriculture. In many respects, this opportunity for expansion appears to have been the primary interest and drive of the university with respect to Giyani College of Education; there certainly was little interest in the curriculum, students or staff of the college.

In the case of JCE-Wits, JCE was the stronger partner and already occupied the attractive JCE campus which was also the site of a prestigious music observatory. As mentioned previously, the small university staff from the Department of Education were simply accommodated within the alreadyoccupied JCE campus. Wits University made little public claim about the campus even though this facility now fell under its jurisdiction; but JCE remained in charge.

In the case of the technikons, the combined physical facilities offered a powerful, single site for technikon education but since both sites had significant student numbers, the added benefits were not clear. Rather, the costs of aligning the two facilities in terms of technological and administrative infrastructure presented much more contention than any perceived opportunities offered for expansion. In the case of the Veterinary Sciences, the take-over of the small MEDUNSA facility made physical space a nonissue. The MEDUNSA staff and students simply fitted into the large and impressive University of Pretoria facilities at Onderstepoort; in other words, the MEDUNSA facilities were left behind and had no substantial influence on the merger negotiations or its outcomes. And in the case of SACTE-UNISA, the physical facilities occupied by SACTE formed the focus of intense and protracted negotiations among three partners: UNISA, the GDE and the University of Pretoria. Despite being a distance education institution, UNISA required added facilities for its staff and specialist facilities (like laboratories) for scheduled practicals with its science students. The GDE claimed that the

physical facilities legally belonged to the provincial government (as in the college dispensation) and therefore saw this as an opportunity to accommodate its expanding regional activities. The facilities were housed on what became University of Pretoria property when it incorporated the Pretoria College of Education (01(P), on whose campus the SACTE facilities were located. To make this picture more complicated, some of the SACTE offices were located inside the Pretoria College of Education buildings, and the laboratories were shared by students of the two former colleges. In short, the SACTE-UNISA case demonstrated the complexity of physical space in the context of mergers. It appears that negotiations among the three claimants 
(UNISA. GDE and UP) might lead to UNISA being granted parking space on the UP site in exchange for the SACTE facilities, with the GD being offered a substantial sum of money by UP in exchange for the SACTE facilities.

These negotiations have as yet not been concluded. Similarly, the interest of the Limpopo provincial Department of Education in the Giyani College of

Education facility has also extended the debates on physical facility ownership with the University of Venda. And the newly proposed merger of the Universities of Venda, the North and MEDUNSA will surely overshadow the relatively smaller interest in the Giyani campus in the next few years. The outcomes remain uncertain.

\section{Lessons learned}

Our thesis is that the initiation, form and outcomes of mergers are dependent on the interaction of governmental macro-politics and institutional micropolitics within specific merger contexts. Yet there are clear guidelines that emerge from the five case studies that suggest conditions under which mergers could be more or less effective in attaining institutional goals. The Johannesburg College of Education (JCE), a small college being incorporated into a large university, is a 'positive case' of how an institution can secure its position within a larger entity.

With this case in mind, it can be confidently asserted that the form and outcome of a merger is contingent on the following factors:

(1) a strong and reliable institutional leadership whose authority is respected across the various institutions concerned, including government and the two institutions targeted for a merger.

It is very clear from the evidence that weak leadership at the time of a merger would invariably damn the lesser institution going into the merger. In the case of the Veterinary School of MEDUNSA, the Giyani College, the Technikon Natal and the SACTE, there was no strong, visible and respected leadership that could make the demands on the merger partner that would strengthen the hand of the weaker institution. The SACTE leadership was not highly regarded by UNISA or the GDE; the Giyani leadership was non-existent and not highly regarded by UNIVEN; the MEDUNSA Veterinary Faculty had no leadership to speak of going into the merger; and the leadership at Technikon Natal was not visible and assertive in the face of intense public hostility by unions on the other side. Rather, the TN leadership appeased throughout this process to have backed down into an insular process during which it simply continued 'business as usual' with their own accounting and administrative processes well beyond the scheduled date of the merger.

(2) a strong and verifiable financial position on the part of the entity being merged; the stronger the entity (small or large) being merged in terms of financial resources, the greater its capacity to negotiate a favourable position for its staff, students and curriculum. 
Both SACTE and JCE had relatively healthy financial positions. However, the financial position of SACTE was not decisive per se in determining the outcome of the merger; this is because of the lack of strategic leadership (next point) going into the merger. But it did make a difference in the case of JCE with very firm guidelines from the college that reserves, for example, would be restricted for use in teacher education. In all the other cases, the weaker partner had severe financial difficulties and this compromised the bargaining power of the institution; the clearest example is the Technikon Natal. Unsurprisingly, therefore, in the latter case the Vice-Chancellor of the new institution was the incumbent at MLS.

(3) a strong and strategic leadership that, having accepted the broad macropolitical arrangements for incorporation, then decides to deploy its energy and resources for optimal positioning of its staff, students and curriculum in the merged entity.

The institutions that enjoyed relative success, like JCE, were ones that accepted the broad terms of merger and incorporation and then positioned their institutions for optimal benefits in the newly envisaged structure. The longer the leadership resisted the very notion of merger, the weaker the position of the institution it defended in the face of the inevitable. It might very well be the case, too, with UNISA; the longer the institution delays the incorporation process with other distance education units, the longer it creates tension, confusion and dissent within and outside of the institution weakening its overall bargaining position and attractiveness when the merger actually happens. By contrast, institutions that, having initially resisted, then positioned themselves to deal with the modalities of merger,were better able to create favourable conditions for their staff and students.

(4) a strong and reliable student enrolment which, together with other factors, create a favourable basis for negotiations especially if the other entity has fewer students or, worse, declining numbers of students at the time of the merger discussions.

In a system that funds institutions on the basis of student enrolments, the numbers of students becomes a very critical component of the merger outcome. In the case of Giyani-Venda, the fact that student teacher numbers were down in both institutions meant that the more powerful and assertive partner (UNIVEN) could simply override its weaker partner in the quest for stronger overall numbers and, as the case showed, additional physical facilities. In the case of JCE-Wits, the student numbers were decisive in determining the position of the JCE in the merger since Wits had steadily dwindling numbers threatening the very positions of its academic staff. Similarly, the MEDUNSA student numbers were very low in relation to staffing and this must have contributed to its already weak financial position. In the case of the technikons student numbers were more or less equal, and played little role in the merger outcome - other factors did, however, play a more determining role. In the same way, the larger numbers of SACTE did little to elevate their overall position in the merger because of other factors. 
(5) a strong and loyal staff complement whose commitment and participation is ensured and sustained by the institutional leadership throughout the merger process in a consistent and transparent manner.

Staff strength and loyalty is also a necessary, though not sufficient condition, for strengthening the position of the smaller or weaker entity in a merger. In the case of JCE, there is a long-established tradition of trust, openness, collegiality and support that binds the management and staff together as a strong unit. In all the other cases, such traditions did not exist in the same way. More often than not, there were suspicions and distrust of management, and this weakened the leadership of the majority of those institutions that entered merger negotiations. Time after time the research team ran into accusations of lies, disloyalty and distrust leveled at institutional leadership except in the JCE case.

(6) a well-planned and well-time merger implementation that proceeds at an appropriate period of time in the life-cycle of one or more of the partner institutions.

The outcome of a merger is also contingent on the timing of the merger process. In the JCE case, it is very clear that the relative strength of JCE was effective in the merger process because college enjoyed this elevated authority at the very moment that the Wits Education Department was declining in status, position and leadership within the University of the Witwatersrand. Ten years ago, for example, it would have been inconceivable that Wits University's Faculty of Education, by far a leading education facility in South Africa at the time, would have been marginalised within a college campus organisation.

(7) a strong and interventionist government that intervenes proactively, decisively and appropriately to ensure that the merger process stays on track, especially in times where the proposed merger threatens to disintegrate.

It is very clear that the weak provincial government of the Limpopo province is a critical factor in the ongoing (June 2002) dispute and unresolved merger of the Giyani College of Education and the University of Venda. The provincial authority in this case has simply not responded to the disintegration of the merger; it has not provided leadership to either institution and has not outlined a clear plan with timelines for what should happen, and when. In the process, Giyani College has simply been disintegrating as one of the prime facilities for innovative teacher education over the past two decades; top college academics have left the site, and the curriculum has been effectively demolished. By contrast, the incisive intervention of the national government in the case of JCE steered the institution towards Wits University in very clear terms, and the college leadership then adopted its strategic position during inter-institutional negotiations. But both the provincial government (the GDE) and the national government failed to intervene in the loss and demise of SACTE, losing much of the college expertise and curriculum in the face of an indifferent UNISA that simply and selectively claimed the material resources of the now defunct college. 


\section{Conclusion}

The research presented in this article disturbs that most cherished assumption of policy-makers that policy implementation is a rational-technical process in which official policy (the formal intentions of government) is a mirror image of institutional practice (the ways in which institutions respond to or change in relation to government intentions). Merger policy, as we have shown, is seldom merger practice. ${ }^{11}$ Or, in the words of Eastman and Lang, 'the merger plan is not the merger. ${ }^{12}$ Any continuing notion that governmental policy is rational, coherent and congruent with institutional practice enjoys no support from this and related empirical work in higher education. ${ }^{13}$ Moreover, definitive claims across contexts about what mergers can and cannot deliver are clearly not supported by this national study. Merger outcomes, rather, depend on the nature and intensity of governmental and institutional interactions on political terms; and as such, merger outcomes are not determinable in advance. It all depends.

\section{Notes and references}

* Jonathan Jansen is Dean of the Faculty of Education at the University of Pretoria.

1. J. D. Jansen, N, Bandi, S. Chalusu. M. Lethoko, C. Sehoole and V. Soobrayan (2002). Mergers in Higher Education: Lessons Learned in Transitional Contexts (Pretoria: University of South Africa Press).

2. D. L. Zekan (1994). 'The Implications of a Public Institutional Merger', in J. Marlin. J.E. Samels \& Associates (eds) Merging Colleges for Mutual Growth: A New Strategy for Academic Mergers (Baltimore: Johns Hopkins University Press), pp. 117-31.

3. G. Harman (1993), 'A Merger that Failed', Higher Education Quarterly, 47 (2), pp. $120-41$

4. K. Harman and V. L. Meek (2002), 'Introduction to Special Issue: Merger Revisited: International Perspectives on Mergers in Higher Education', Higher Education, 44 (1), pp. 1-4.

5. Jansen (2002), op. cit.

6. Correspondence from Consultants on Merger of Natal Technikon and ML Sultan Technikon' to the Department of Education, 26 March 2002.

7. W. Massy (1998), 'Remarks on Restructuring Higher Education', in Report of the National Commission on the Cost of Higher Education, Straight Talk about College Costs and Prices (Westport: The American Council on Education and the Oryx Press).

8. N. Carrim, D. Postma and P. Christie (2002). 'Johannesburg College of Education: Linking University and College Teacher Education', in K. Lewin, M. Samuel and Y. Sayed (eds) Changing Patterns of Teacher Education in South Africa: Policy, Practice and Prospects (Cape Town: Heinemann Publishers). 9. Ibid.

10. H.R. Hay, M. Fourie and J.F. Hay (2001). 'Are Institutional Combinations, Mergers or Amalgamation the Answer? An Investigation into Staff Perceptions', South African Journal of Higher Education, 15 (1), pp. 100-8. Hay, Driekie and M. Fourie (2002), 'Preparing the Way for Mergers in South African Higher and Further Education Institutions: An Investigation into Staff Perceptions', Higher Education, 44 (1), pp. 115-31. 
11. Jansen (2002), op. cit.

12. J. Eastman and D. Lang (2001), Mergers in Higher Education: Lessons From Theory and Experience (Toronto: University of Toronto Press), 13, P. Trowler (2002) (ed). Higher Education Policy and Institutional Change: Intentions and Outcomes in Turbulent Environments (Buckingham: Open University Press). 